\title{
Carbothermic reduction synthesis of red phosphorus-filled 3D carbon material as a high-capacity anode for sodium ion batteries
}

Jie Sun, ${ }^{1}$ Hyun-Wook Lee, ${ }^{2}$ Mauro Pasta, ${ }^{3}$ Yongming Sun, ${ }^{1}$ Wei Liu, ${ }^{1}$ Yanbin Li, ${ }^{1}$ Hye Ryoung Lee, ${ }^{1}$

\author{
Nian Liu, ${ }^{1}$ Yi Cui ${ }^{1,4^{*}}$ \\ ${ }^{1}$ Department of Materials Science and Engineering, Stanford University, Stanford, California 94305, \\ USA, ${ }^{2}$ School of Energy and Chemical Engineering, Ulsan National Institute of Science and Technology \\ (UNIST), Ulsan 44919, Korea, ${ }^{3}$ Department of Materials, University of Oxford, 16 Parks Road, Oxford \\ OX1 3PH, UK, ${ }^{4}$ Stanford Institute for Materials and Energy Sciences, SLAC National Accelerator \\ Laboratory, 2575 Sand Hill Road, Menlo Park, California 94025, USA.
}

\begin{abstract}
Phosphorus is an attractive negative electrode material for sodium ion batteries due to its high theoretical specific capacity of $2,596 \mathrm{mAh} \mathrm{g}^{-1}$. However, it suffers poor conductivity $\left(10^{-12} \mathrm{~S} \mathrm{~m}^{-1}\right)$, slow reaction dynamics, and large volume expansion ( $440 \%)$ during the sodiation process, leading to rapid capacity decay upon cycling. Great attention has been devoted to improving the electrical conductivity via mixing phosphorus particles with conductive carbon materials, yet little emphasis has been placed on addressing the volume expansion issue, which may leads to the loss of electrical contact between the active material and the current collector, and the sequent deterioration of the overall electrochemical performance. Here, we demonstrate a carbothermic reduction method to fabricate ultrafine red phosphorus particles $(\sim 10 \mathrm{~nm})$ embedded in a three-dimensional carbon framework, in which numerous interconnected nanopores are generated accompanied by the carbonization of polyethylene glycol. During discharge/charge processes, nanosized phosphorus particles accommodate the large stress without cracking, and decrease the diffusion length, as well as connect strongly with carbon framework, resulting in an improved conductivity, a reversible specific capacity of $1,027 \mathrm{mAh} \mathrm{g}^{-1}$ (at $0.2 \mathrm{C}$ ) and high capacity retention of $88 \%$ over 160 cycles.
\end{abstract}

* Corresponding author: yicui@stanford.edu. 
Keywords: red phosphorus; three dimensional structure; carbothermic reaction; sodium-ion batteries.

\section{TOC graphic}
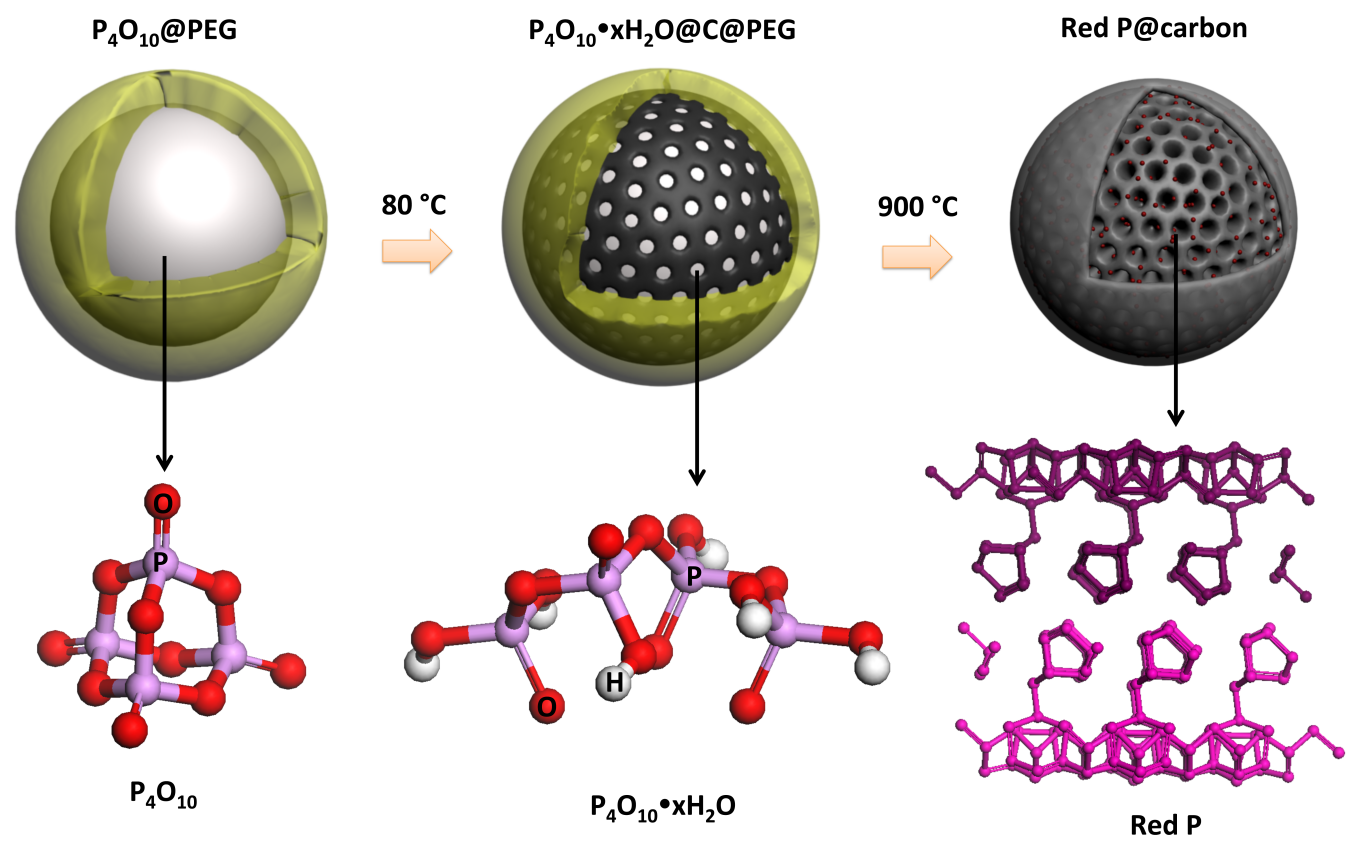


\section{Introduction}

Growing energy needs and depletion of fossil-fuel resources demand the pursuit of sustainable energy alternatives, including both renewable energy sources and sustainable storage technologies. Therefore, it is essential to consider material abundance, eco-friendly synthetic processes and performance when designing new electrochemical storage systems. Sodium ion batteries (SIBs) have recently received a lot of attention as a low-cost and environmentally friendly alternative to lithium ion batteries (LIBs), ${ }^{[1-3]}$ due to the ready availability of sodium resources and the similar chemistry of sodium and lithium ions. ${ }^{[4,5]}$ Although SIB and LIB share many technical similarities in cathodes and electrolytes, ${ }^{[6-8]}$ adapting LIB anode materials to SIBs has revealed an unsuccessful strategy. The representative example is the Li-Si alloy anode, which can store $4.4 \mathrm{Li}$ per $\mathrm{Si}$, and deliver a specific capacity of 4,200 $\mathrm{mAh} \mathrm{g}^{-1} \cdot{ }^{[9]}$ However, Si cannot be electrochemically sodiated, in spite of the existence of Na-Si alloys. ${ }^{[10]}$ Moreover, it is also difficult to find crystalline host anode materials for Na-ion insertion reaction partially because of the large diameter of $\mathrm{Na}(2.04 \AA)$ compared to $\mathrm{Li}(1.52 \AA)$. For example, Na ions cannot be intercalated into the two-dimensional layered graphite. ${ }^{[11]}$

Phosphorus (P) electrochemically reacts with $\mathrm{Na}$ to form $\mathrm{Na}_{3} \mathrm{P}$, and delivers a theoretical specific capacity of $2596 \mathrm{~mA} \mathrm{~h} \mathrm{~g}^{-1},{ }^{[12]}$ which is much higher than other anode candidates, such as germanium $\left(\mathrm{Na}_{15} \mathrm{Ge}_{4}, 369 \mathrm{~mA} \mathrm{~h} \mathrm{~g}{ }^{-1}\right),{ }^{[13]}$ tin $\left(\mathrm{Na}_{15} \mathrm{Sn}_{4}, 847 \mathrm{~mA} \mathrm{~h} \mathrm{~g}^{-1}\right),{ }^{[14]}$ lead $\left(\mathrm{Na}_{15} \mathrm{~Pb}_{4}, 485 \mathrm{~mA} \mathrm{~h} \mathrm{~g}^{-1}\right),{ }^{[15]}$ and antimony $\left(\mathrm{Na}_{3} \mathrm{Sb}, 660 \mathrm{~mA} \mathrm{~h} \mathrm{~g}^{-1}\right)^{[16]}$. Moreover, red $\mathrm{P}$ is earth-abundant and nontoxic. However, it is synthesized industrially starting from the toxic and very reactive white $\mathrm{P}$, it suffers from a poor electrical 
conductivity $\left(10^{-12} \mathrm{~S} \mathrm{~m}^{-1}\right)^{[17]}$ and has a large volume expansion ( 440\%) during the sodiation process, leading to rapid capacity decay upon cycling. To improve the electrical conductivity, commercial phosphorus particles have been mixed with various carbon materials, ${ }^{[18-24]}$ such as, carbon black, ${ }^{[19-21]}$ carbon nanotubes and ${ }^{[22,23]}$ graphene ${ }^{[24]}$. However, there is little success on solving the other problem i.e. the large volume expansion upon sodiation, similarly as Si anode for LIBs, ${ }^{[25,26]}$ which leads to the loss of electrical contact of active materials and deterioration of the electrochemical performance upon cycling.

In order to simultaneously solve the problems of the poor conductivity, large volume expansion and harmful synthesis process, herein, we demonstrate a synthesis strategy of carbothermic reduction of $\mathrm{P}_{4} \mathrm{O}_{10}$ into $\mathrm{P}$, resulting in embedding red $\mathrm{P}$ nanoparticles in a three-dimensional (3D) carbon framework (P/C composite). Such a design has multiple advantages: (1) The resulting, ultrafine red $\mathrm{P}$ particles, with a diameter of $\sim 10 \mathrm{~nm}$, not only minimize the diffusion distance of sodium ions, but also allow for a favorable accommodation of the large volume changes without the fracturing that can occur in bulk or micron-sized materials. (2) Red P particles are electrically connected to the conductive 3D carbon framework via P-O-C bonds: the carbon framework functions as an electrical highway and a mechanical backbone, so that all the red P particles are electrochemically active. (3) The interlinked channels are easily filled with electrolyte, thus facilitating the transportation of a large flux of $\mathrm{Na}$ ions. (4) A scalable and bottom-up method is applied to fabricate the designed structure, by which $\mathrm{P}_{4} \mathrm{O}_{10}$ is the substitute for the toxic white P. 


\section{Materials and methods}

2.1 Synthesis of $\mathbf{P} / \mathbf{C}$ composite. $\mathrm{P}_{4} \mathrm{O}_{10}$ and polyethylene glycol (PEG) (MW, 1500) were purchased from Sigma-Aldrich. Firstly, solid PEG transformed into liquid by heating at $80{ }^{\circ} \mathrm{C}$ in a vacuum oven. White powdered $\mathrm{P}_{4} \mathrm{O}_{10}(2.5 \mathrm{~g})$ was added into the above liquid PEG (7.5 g). After 40 min at $80{ }^{\circ} \mathrm{C}$ in the vacuum oven, its color changed to black because the super absorbent $\mathrm{P}_{4} \mathrm{O}_{10}$ extracted the water from PEG and polymerized to a long chain molecule of polyphosphoric acid, meanwhile the PEG was carbonized by losing $\mathrm{H}_{2} \mathrm{O}$. Subsequently, the intermediate products were transferred into an alundum boat (Fisher Scientific) and calcined at $900{ }^{\circ} \mathrm{C}$ with a ramping rate of $15{ }^{\circ} \mathrm{C} / \mathrm{min}$ and an argon flow rate of $5 \mathrm{sccm}$ (Standard Cubic Centimeter per Minute) under sunlight. When some red substance appeared onto the inner wall of the quartz tube (about $0.5 \mathrm{~h}$ at $900{ }^{\circ} \mathrm{C}$ ), the boat was moved to the $250{ }^{\circ} \mathrm{C}$ zone in the quartz tube and remained for $1 \mathrm{~h}$ under sunlight (Supplementary Information, Figure S1). The low temperature $\left(250^{\circ} \mathrm{C}\right)$ was carried out to condense the produced red $\mathrm{P}$, according to its melting point of $590^{\circ} \mathrm{C}$. Sunlight catalyzes the production of red $\mathrm{P}$ instead of the toxic and flammable white $\mathrm{P}$. The above mentioned procedure was repeated for 10 times. Finally, the $\mathrm{P} / \mathrm{C}$ composite was obtained after washing with a $5 \% \mathrm{NaOH}$ aqueous solution to remove the residual $\mathrm{P}_{4} \mathrm{O}_{10}$. For comparison, the carbon framework alone was obtained by oxidizing red $\mathrm{P}$ via heating at $350{ }^{\circ} \mathrm{C}$ for $2 \mathrm{~h}$ in air, and then washing by a $5 \%$ $\mathrm{NaOH}$ aqueous solution to remove the phosphorus oxides. Pure red $\mathrm{P}$ was prepared in the same conditions by changing the Ar flow rate to $50 \mathrm{sccm}$, and collected from the inner wall of the quartz tube.

2.2 Electrochemical Characterization. The battery performance was evaluated by galvanostatic cycling of coin (CR 2032) cells with the P/C composite as the working electrode and sodium foil as the 
counter/reference electrode. The working electrodes were made using a typical slurry method with $\mathrm{P} / \mathrm{C}$ powders, carbon black and polyvinylidene fluoride (PVDF) binder with a mass ratio of 85:5:10 in $\mathrm{N}$-methyl-pyrrolidone (NMP) solvent; the mass loading of active material ( $\mathrm{P} / \mathrm{C}$ composite) was $\sim 2.5 \mathrm{mg}$ $\mathrm{cm}^{-2}$. The electrolyte consisted of $1.0 \mathrm{~mol} \mathrm{~L}^{-1} \mathrm{NaPF}_{6}$ in an ethylene carbonate (EC)- diethyl carbonate (DEC) solution with addition of $10 \%$ fluoroethylene carbonate (FEC) in order to form a stable SEI film. ${ }^{[27]}$ The electrochemical data were collected using an Arbin MSTAT battery test system within the potential range $0.01-1.5 \mathrm{~V}$ (vs. $\mathrm{Na} / \mathrm{Na}^{+}$) at various current densities. The specific capacity was calculated based on the total weight of phosphorus and carbon.

\section{Results and Discussion}

The process for the fabrication of the $\mathrm{P} / \mathrm{C}$ composite, featuring ultrafine red $\mathrm{P}$ particles $(\sim 10 \mathrm{~nm})$ embedded in 3D carbon matric, is schematically depicted in Figure 1. Firstly, white $\mathrm{P}_{4} \mathrm{O}_{10}$ particles were coated with a polymer shell of PEG in a vacuum oven at $80{ }^{\circ} \mathrm{C}$ (Figure 1a). Tens of minutes later (Figure 1b), the mixture turned black due to dehydration and subsequent carbonization of the PEG. Meanwhile, $\mathrm{P}_{4} \mathrm{O}_{10}$, as a super-dehydrant, reacted with the water from PEG and polymerized to polyphosphoric acid, in the form of chain molecules with the general formula $\mathrm{H}\left(\mathrm{HPO}_{3}\right)_{\mathrm{n}} \mathrm{OH}{ }^{[28]}$ (Supplementary Information, Figure S2), leading to the formation of 3D channels. To achieve the final structure (Figure 1c), PEG was further carbonized to form a 3D-structured carbon framework, while $\mathrm{P}_{4} \mathrm{O}_{10}$ was carbothermically reduced to red $\mathrm{P}$ (equation (1)), which can occur at a temperatures higher than $743{ }^{\circ} \mathrm{C}$. Considering the endothermic nature of this reaction $(\Delta \mathrm{H}>0)$, the temperature was 
set at $900{ }^{\circ} \mathrm{C}$, to increase the kinetic rate, as shown below:

$$
P_{4} O_{10}(s)+10 C(s) \stackrel{900^{\circ} \mathrm{C}}{\longrightarrow} 4 P(s, r e d)+10 C O(g), \Delta \mathrm{H}=1808.4 \mathrm{~kJ} \mathrm{~mol}^{-1}, \Delta \mathrm{G}=-280.1 \mathrm{~kJ} \mathrm{~mol}^{-1} \text { (1) }
$$

In this final structure (Figure 1c), the 3D carbon framework not only improves the electrical conductivity, but also provides a buffer space for the volumetric expansion of red $\mathrm{P}$ nanoparticles during the sodiation process. It is crucial to provide enough buffer space for accommodating the volumetric expansion. The void space is created by the volumetric shrinkage from $\mathrm{P}_{4} \mathrm{O}_{10}$ to red $\mathrm{P}$ and the carbon consumption. The volumetric shrinkage ratio going from $\mathrm{P}_{4} \mathrm{O}_{10}$ to red $\mathrm{P}$ is estimated to be 4.52 , which matches well the volumetric expansion ratio from red $\mathrm{P}$ to $\mathrm{Na}_{3} \mathrm{P}$ (4.37), as shown in equation (2). This suggests that there is an adequate void space for the volume expansion without cracking the $3 \mathrm{D}$ carbon framework.

Table 1. Density and molar volume of $\mathrm{P}_{4} \mathrm{O}_{10}$, red $\mathrm{P}$ and $\mathrm{Na}_{3} \mathrm{P}$.

\begin{tabular}{cccc}
\hline & $\mathbf{P}_{\mathbf{4}} \mathbf{O}_{\mathbf{1 0}}$ & $\mathbf{R e d} \mathbf{P}$ & $\mathbf{N a}_{\mathbf{3}} \mathbf{P}$ \\
\hline Density $\left(\mathrm{g} / \mathrm{cm}^{3}\right)$ & 2.39 & 2.36 & 1.74 \\
Molar volume $\left(\mathrm{cm}^{3} / \mathrm{mol}(\mathrm{P})\right)$ & 59.414 & 13.135 & 57.471 \\
\hline
\end{tabular}

${ }^{\dagger}$ Molar volume calculated based on $1 \mathrm{~mol} \mathrm{P}$ atom.

$$
\frac{V_{\text {mol }(P)}\left(P_{4} O_{10}\right)}{V_{\operatorname{mol}(P)}(R P)}=4.52>\frac{V_{\text {mol }(P)}(N a P)}{V_{\operatorname{mol}(P)}(R P)}=4.37
$$

The morphology of the P/C composite was characterized by scanning electron microscopy (SEM) 
and transmission electron microscopy (TEM), as shown in Figure 2. The P/C composites have a spherical shape, with a diameter ranging from 20 to $35 \mathrm{~m}$ (Figure 2a). The detailed morphology is shown in the magnified SEM image in Figure 2b, where many pinholes with a diameter of about 100 $\mathrm{nm}$ can be clearly observed on the surface, suggesting the presence of inner empty channels. In order to further characterize the channels, a $\mathrm{P} / \mathrm{C}$ sphere was cut open by grinding to expose the 3D interconnected inner channels (Figure 2c). The Energy dispersive spectroscopy (EDS) mapping images in Figures 2d-2f, reveal the distributions of elemental phosphorous and carbon. Carbon is uniformly dispersed (Figure 2e), whereas phosphorous is located along the channels (Figure 2d). As shown in the overlay EDS mapping (Figure 2f), the border of the $\mathrm{C}$ dots is slightly wider than that of $\mathrm{P}$, which illustrates that red P filled in the 3D channels of the carbon framework. The HRTEM image of a broken particle (Figure 2g) shows that the diameter of the inner channels range from several tens to hundreds of nanometers. In Figure 2h, amorphous P clusters, with $\sim 10 \mathrm{~nm}$ in size, are uniformly embedded in a carbon framework. Large spheres are partially coated with a thin carbon shell (Figure 2a-b), which is less than 10 nanometer thick and show a certain degree of graphitization (Figure 2i). In order to further study its hierarchical porosity, we performed nitrogen adsorption/desorption isotherm measurement for the $\mathrm{P} / \mathrm{C}$ composite. The isotherms reveal a relatively high Brunauer-Emmett-Teller (BET) specific surface area (SSA) of $698.46 \mathrm{~m}^{2} \mathrm{~g}^{-1}$ (Supplementary Information, Figure S3). The Barrett-Joyner-Halenda (BJH) pore size distribution plot indicates that the $\mathrm{P} / \mathrm{C}$ composite has both micropores and mesopores (Supplementary Information, Figure S4). The large surface area and rich porosity of the hierarchical porous structure should enhance Li ion diffusivity leading to an improved 
high rate capability.

The structure of the $\mathrm{P} / \mathrm{C}$ composite was further studied by thermogravimetric analysis (TGA), X-ray photoelectron spectroscopy (XPS) and Raman spectroscopy. Figure 3a shows the TGA of pure red P under an atmosphere of $20 \% \mathrm{O}_{2}$ and $80 \%$ Ar. A weight gain can be observed at $250{ }^{\circ} \mathrm{C}$, corresponding to the oxidation of red phosphorus, followed by a sharp weight loss between $450{ }^{\circ} \mathrm{C}$ and $500{ }^{\circ} \mathrm{C}$, due to the combustion of red phosphorus to $\mathrm{P}_{2} \mathrm{O}_{5}$ gas. The TGA of the $\mathrm{P} / \mathrm{C}$ composite shows a weight increase in the $400-500{ }^{\circ} \mathrm{C}$ range, showing that the inner red-P particles were oxidized but burned. The carbon framework alone shows a dramatic mass loss in the $550-800{ }^{\circ} \mathrm{C}$ range, resulting from the oxidation of carbon and the emission of $\mathrm{CO}_{2} / \mathrm{CO}$ gas. Similarly, the weight loss in the $\mathrm{P} / \mathrm{C}$ composite above $550{ }^{\circ} \mathrm{C}$ is attributed to the oxidation of the carbon framework, not the combustion of red-P. The oxidation temperature of red-P in the $\mathrm{P} / \mathrm{C}$ composite is higher than pure red-P, indicating that the red-P filled is more stable in the carbon framework. Therefore, the thermal stability of the composite is expected to be sufficient for battery applications. The $\mathrm{P}$ content in the composite is $36 \mathrm{wt} \%$ according to the TGA measurement (Supplementary Information, Figure S5).

The Raman spectrum (Figure 3b) of the P/C composite exhibits both the characteristic G- ( $\sim 1600$ $\left.\mathrm{cm}^{-1}\right)$ and D- $\left(\sim 1350 \mathrm{~cm}^{-1}\right)$ bands of the carbon framework and the $\mathrm{P}_{7} / \mathrm{P}_{9}$ caged feature in amorphous red-P in the $300-500 \mathrm{~cm}^{-1}$ region. ${ }^{[18]}$ This confirms that $\mathrm{P}$ is present only as red $\mathrm{P}$, with no signs of $\mathrm{P}_{4} \mathrm{O}_{10}$. In regard to carbon, the $\mathrm{G}$ band corresponds to the first-order scattering of the E2g mode observed for $s p^{2}$ carbon domains, while the pronounced $\mathrm{D}$ band is caused by structural defects or edges that can break the symmetry and selection rules. ${ }^{[29,30]}$ The intensity ratio of $\mathrm{D}$ band to $\mathrm{G}$ band $\left(\mathrm{I}_{\mathrm{D}} / \mathrm{I}_{\mathrm{G}}\right)$ is usually used to 
measure the graphitization degree of carbon materials. The $\mathrm{P} / \mathrm{C}$ composite has the partial-overlapped $\mathrm{G}$ and $\mathrm{D}$ bands with an $\mathrm{I}_{\mathrm{D}} / \mathrm{I}_{\mathrm{G}}$ value of ca. 2.88 , indicating that the carbon framework has a low graphitization degree with disordered graphene layers. After removing red-P, the $\mathrm{I}_{\mathrm{D}} / \mathrm{I}_{\mathrm{G}}$ value is almost the same as that in the $\mathrm{P} / \mathrm{C}$ composite, but the location of the $\mathrm{G}$ peak shifts to a low wavenumber of 1588 $\mathrm{cm}^{-1}$ from $1601 \mathrm{~cm}^{-1}$. Therefore, the red-shift of $\mathrm{G}$ band by $13 \mathrm{~cm}^{-1}$ is attributed to the loss of electrical contact between red-P nanoparticles and carbon framework.

The interaction between red-P nanoparticles and the carbon framework was further investigated by X-ray photoelectron spectroscopy (XPS). Two peaks centered at $130.2 \mathrm{eV}$ and $134.2 \mathrm{eV}$ were observed in the $\mathrm{P} 2 p$ XPS spectrum of the $\mathrm{P} / \mathrm{C}$ composite (Figure 3c). The peak in the $\sim 130 \mathrm{eV}$ region is attributed to the $\mathrm{P} 2 p_{3 / 2}$ and $\mathrm{P} 2 p_{1 / 2}$ from P-P bond. The relatively broad higher binding energy peak at $134.2 \mathrm{eV}$ corresponds to the P-O-C bonds. In contrast, in the P2 $p$ spectrum of the pure red-P, only one peak, assigned to the P-P bond, is observed at $130.2 \mathrm{eV}$. In Figure 3d, the $\mathrm{C} 1 s$ spectrum of the $\mathrm{P} / \mathrm{C}$ composite can be fitted to the mainly non-oxygenated $s p^{2}(284.5 \mathrm{eV})$ and $s p^{3}(285.2 \mathrm{eV})$ carbon, and the C-O-P bond $(286.1 \mathrm{eV})$. After removing red-P particles, the residual carbon framework loses the C-O-P peak at around $286.1 \mathrm{eV}$. This result indicates that $\mathrm{O}$ combine more strongly with $\mathrm{P}$ than $\mathrm{C}$. As we previously mentioned, both red and black-P based anodes in SIBs, undergo a large volumetric change with breaking and regeneration of P-P bonds, leading to the loss of electrical contact of P particles with the conductive carbon materials. ${ }^{[18,27]}$ Sodiation in the carbon host without breaking $\mathrm{C}-\mathrm{C} / \mathrm{C}=\mathrm{C}$ bonds is attributed to higher bond energy of $\mathrm{C}-\mathrm{C} / \mathrm{C}=\mathrm{C}$ bond $(346 / 602 \mathrm{~kJ} / \mathrm{mol})$ than that of $\mathrm{P}-\mathrm{P}$ bond $(201 \mathrm{~kJ} / \mathrm{mol})$. The high bond energy of P-O-C bonds (Supplementary Information, Table S1) enables red P particles to bind 
strongly with the carbon framework via $\mathrm{O}$ atoms, and therefore helps maintain the electrical contact during electrochemical cycling.

It is known that red-P exists as an intermediate state between amorphous and crystalline, being an intermediate phase between white and purple phosphorus, and most of its properties have a range of values. In our work, the XRD spectrum (Figure 4) shows the red-P is close to purple-P (mp-715463, IUCr), in which $\mathrm{Na}$ ion can diffuse through three-dimension channels (as labeled in Figures $\mathbf{4 b - 4 d}$ ) rather than only one channel in black-P ${ }^{[27]}$, leading to high rate capability.

The electrochemical performance of the $\mathrm{P} / \mathrm{C}$ composite and red-P were tested in a two electrode, coin-cell setup using a $\mathrm{Na}$ metal counter electrode, within the potential range of 1.5 to $0.01 \mathrm{~V}$ and at 0.2 $\mathrm{C}$ rate (Figure 5a). The first discharge cycle shows two distinct electrochemical processes. The first sloping region between $1.1 \mathrm{~V}$ and $0.5 \mathrm{~V}$ corresponds partially to the insertion of $\mathrm{Na}$ ions into the crystalline part of red-P and partially to the irreversible formation of the SEI layer. The coulombic efficiency of the first-cycle is about $76 \%$. The following plateau is located at $0.25 \mathrm{~V}$, corresponding to the conversion reaction from red-P to $\mathrm{Na}_{3} \mathrm{P}$. In the following cycles, the sloping region between 1.1-0.5 $\mathrm{V}$ is reduced significantly, as the SEI layer has formed and the initial trapping by $\mathrm{P}$ has been saturated.

The carbon framework alone was also tested in the same conditions and exhibits a specific capacity of only $180 \mathrm{mAh} \mathrm{g}^{-1}$ (see Supplementary Information, Figure S7). Here we report the specific capacity calculated based on the total mass of red-P and carbon $\left(\mathrm{C}_{\mathrm{P} / \mathrm{C}}\right)$, and the weight of red $\mathrm{P}$ only $\left(\mathrm{C}_{\mathrm{P}}\right)$. The comparison with the literature is summarized in Supplementary Information, Table S2.

The $\mathrm{P} / \mathrm{C}$ composite exhibits an initial reversible $\mathrm{C}_{\mathrm{P}}$ specific capacity of $2853 \mathrm{mAh} \cdot \mathrm{g}^{-1}\left(\mathrm{C}_{\mathrm{P} / \mathrm{C}}, 1027\right.$ 
$\mathrm{mAh} \cdot \mathrm{g}^{-1}$ ). After 160 cycles at $0.2 \mathrm{C}, 920 \mathrm{mAh} \mathrm{g}^{-1}$ were still achieved (Figure 5b), corresponding to a high capacity retention of $88 \%$. This results demonstrates that the P-O-C bond improves the connection between the red-P nanoparticles and the carbon framework during the sodiation and desodiation processes. This performance is compared favorably to the literature studies (Supplementary Information, Table S2). The electrochemical performance of a red-P electrode prepared by mixing red P, carbon black and polyvinylidene fluoride (PVDF) binder (30:60:10 wt.\%) was also measured, as shown in Figure 5a. Although the first reversible discharge $C_{\mathrm{P} / \mathrm{C}}$ capacity of the red-P electrode was $\sim 900 \mathrm{mAh} / \mathrm{g}$, its second discharge capacity $\left(\mathrm{C}_{\mathrm{P} / \mathrm{C}}\right)$ decayed to $670 \mathrm{mAh} / \mathrm{g}$, due to the poor conductivity and large volume expansion resulting in the loss of electrical contact with the conductive carbon additive.

Due to its enhanced electrical conductivity, the $\mathrm{P} / \mathrm{C}$ composite showed an outstanding rate capability (Figure 5c). The theoretical specific capacity $\left(\mathrm{C}_{\mathrm{P} / \mathrm{C}}\right)$ of the $\mathrm{P} / \mathrm{C}$ composite is $1049 \mathrm{~mA} \mathrm{~h} \mathrm{~g}{ }^{-1}$, which is calculated based on the theoretical specific capacity of $\mathrm{P}\left(2596 \mathrm{~mA} \mathrm{~h} \mathrm{~g}^{-1}\right)$ and the experimental specific capacity of $\mathrm{C}\left(180 \mathrm{~mA} \mathrm{~h} \mathrm{~g}^{-1}\right)$ at a low current density of $10 \mathrm{~mA} \mathrm{~g}^{-1}$. A reversible capacity of $1027 \mathrm{~mA} \mathrm{~h}$ $\mathrm{g}^{-1}$ was obtained at $0.2 \mathrm{C}\left(210 \mathrm{~mA} \mathrm{~g}^{-1}\right)$, reaching close to the limit. When the current density was

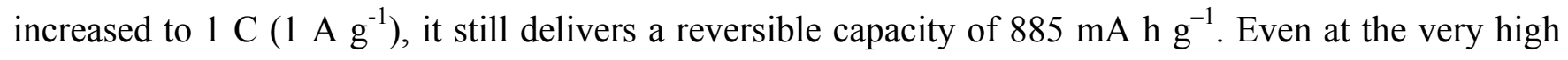
rates of $3.5 \mathrm{C}\left(3.6 \mathrm{~A} \mathrm{~g}^{-1}\right), 6.5 \mathrm{C}\left(7 \mathrm{~A} \mathrm{~g}^{-1}\right)$, and $10 \mathrm{C}\left(10 \mathrm{~A} \mathrm{~g}^{-1}\right)$, the electrode retains a specific capacity of $645 \mathrm{~mA} \mathrm{~h} \mathrm{~g}^{-1}, 480 \mathrm{~mA} \mathrm{~h} \mathrm{~g}^{-1}$ and $340 \mathrm{~mA} \mathrm{~h} \mathrm{~g}^{-1}$, respectively.

To demonstrate the effectiveness of this structural design in improving the electrochemical performance, electrochemical impedance spectroscope (EIS) was performed. Prior to the EIS tests, the 
cells were run for 5 cycles. The tests were then carried out potentiostatically at $1.5 \mathrm{~V} \mathrm{vs} \mathrm{Na}^{+} / \mathrm{Na}$ in the discharged state (Figure 5d). The Nyquist plots of both electrodes consist of a single depressed semicircle in the high-medium frequency region and an inclined line at the low frequency, respectively. The elements in the equivalent circuit include ohmic resistance of the electrolyte and cell components $\left(R_{e}\right)$, surface film resistance $\left(R_{s f}\right)$, charge-transfer resistance at the interface between the electrode and electrolyte $\left(\mathrm{R}_{\mathrm{ct}}\right)$, a constant phase element $\left(\mathrm{CPE}_{\mathrm{i}}\right)$ (surface film (sf), double layer $\left.(\mathrm{dl})\right)$ used instead of pure capacitance due to the depressed semicircle, ${ }^{[18]}$ Warburg impedance $\left(Z_{\mathrm{w}}\right)$, and intercalation capacitance $\left(\mathrm{C}_{\mathrm{int}}\right)$. According to the fitting with this equivalent circuit, the value of $\mathrm{R}_{\mathrm{e}}$ is $8-12 \Omega$ for the both samples, indicating that the cells have been properly fabricated and tested in the same condition. Due to the single semicircle observed, the impedance can be ascribed to the combination of the surface film and charge-transfer resistance $\mathrm{R}(\mathrm{sf}+\mathrm{ct})$. The fitting parameter of $\mathrm{R}(\mathrm{sf}+\mathrm{ct})$ is much lower for the $\mathrm{P} / \mathrm{C}$ electrode (176.4 $\Omega$ ) compared to the red P (391.6 $\Omega$ ), which means that the $\mathrm{P} / \mathrm{C}$ electrode has a faster charge-transfer process than the red-P electrode.

The structural evolution of the $\mathrm{P} / \mathrm{C}$ composite during the electrochemical process was investigated by SEM (Figures 5e). The spherical structure integrity is maintained without cracking after 20 sodiation/desodiation cycles. We attribute the good sodium storage performance of the $\mathrm{P} / \mathrm{C}$ composite to its 3D porous architecture. The channels in the carbon framework not only function as an electrical highway in which sodium ions and electrolyte can be transported, but also give a buffer space allowing the $\mathrm{P}$ particles to expand. 


\section{Conclusions}

In conclusion, we report a facile synthesis method to fabricate a 3D-structured $\mathrm{P} / \mathrm{C}$ composite starting from $\mathrm{P}_{4} \mathrm{O}_{10}$, which performs not only as the template to fabricate the $3 \mathrm{D}$ channels by dehydrating PEG, but also as $\mathrm{P}$ source to produce red-P by carbothermic reduction. Ultrafine red-P nanoparticles accommodate the large stress without cracking, and decrease the diffusion length, as well as the improved conductivity by connecting to carbon framework via $\mathrm{P}-\mathrm{O}-\mathrm{C}$ bonds. The $\mathrm{P} / \mathrm{C}$ composite as anode material for SIBs delivers a capacity of $\mathrm{C}_{\mathrm{P} / \mathrm{C}}$ at $920 \mathrm{mAh} \mathrm{g}^{-1}$ at 160 th cycle with a capacity retention of $88 \%$. Moreover, this $\mathrm{P} / \mathrm{C}$ composite is low cost and stable in air and is expected to be a scalable anode material for the next generation of SIBs.

\section{Acknowledgements}

This work was supported by the Department of Energy, Office of Basic Energy Sciences, Division of Materials Sciences and Engineering, under contract DE-AC02-76SF00515.

\section{References}

[1] Y. Li, L. Mu,Y.-S. Hu, H. Li, L. Chen, X. Huang, Pitch-derived amorphous carbon as high performance anode for sodium-ion batteries, Energy Storage Materials 2 (2016) 139-145.

[2] S.-W. Zhang, W. Lv, C. Luo, C.-H. You, J. Zhang, Z.-Z. Pan, F.-Y. Kang, Q.-H. Yang, Commercial carbon molecular sieves as a high performance anode for sodium-ion batteries, Energy Storage Materials 3 (2016) 18-23.

[3] W. Luo, F. Shen, C. Bommier, H. Zhu, X. Ji, L. Hu, Na-ion battery anodes: materials and electrochemistry, Acc. Chem. Res. 49 (2016) 231-240. 
[4] M.D. Slater, D. Kim, E. Lee, C.S. Johnson, Sodium-ion batteries, Adv. Funct. Mater. 23 (2013) 947-958.

[5] J.M. Tarascon, M. Armand, Issues and challenges facing rechargeable lithium batteries, Nature 414 (2001) 359-367.

[6] P. Barpanda, G. Oyama, S.I. Nishimura, S.C. Chung, A. Yamada, A 3.8-V earth-abundant sodium battery electrode, Nature Commun. 5 (2014) 4358.

[7] B.L. Ellis, W.R.M. Makahnouk, Y. Makimura, K. Toghill, L.F. Nazar, A multifunctional 3.5 V iron-based phosphate cathode for rechargeable batteries, Nature Mater. 6 (2007) 749-753.

[8] H.W. Lee, R.Y. Wang, M. Pasta, S.W. Lee, N. Liu, Y. Cui, Manganese hexacyanomanganate open framework as a high-capacity positive electrode material for sodium-ion batteries, Nature Commun. 5 (2014) 5280.

[9] C.K. Chan, H. Peng, G. Liu, K. McIlwrath, X.F. Zhang, R.A. Huggins, Y. Cui, High-performance lithium battery anodes using silicon nanowires, Nature Nanotechnol. 3 (2008) 31-35.

[10] V.L. Chevrier, G. Ceder, Challenges for Na-ion negative electrodes, J. Electrochem. Soc. 158 (2011) A1011-A1014.

[11] S. Komaba , W. Murata, T. Ishikawa , N. Yabuuchi, T. Ozeki, T. Nakayama, A. Ogata, K. Gotoh, K. Fujiwara, Electrochemical $\mathrm{Na}$ insertion and solid electrolyte interphase for hard-carbon electrodes and application to Na-ion batteries, Adv. Funct. Mater. 21 (2011) 3859-3867.

[12] W.J. Li, S.L. Chou, J.Z. Wang, H.K. Liu, S.X. Dou, Simply mixed commercial red phosphorus and carbon nanotube composite with exceptionally reversible sodium-ion storage, Nano Lett. 13 (2013) 5480-5484.

[13] L. Baggetto, J.K. Keum, J.F. Browning, G.M. Veith, Germanium as negative electrode material for sodium-ion batteries, Electrochem. commun. 34 (2013) 41-44.

[14] H. Zhu, Z. Jia, Y. Chen, N. Weadock, J. Wan, O. Vaaland, X. Han, T. Li, L. Hu, Tin anode for sodium-ion batteries using natural wood fiber as a mechanical buffer and electrolyte reservoir, Nano Lett. 13 (2013) 3093-100.

[15] T.R. Jow, L.W. Shacklette, M. Maxfield, D. Vernick, The role of conductive polymers in alkali metal secondary electrodes, J. Electrochem. Soc. 134 (1987) 1730-1733. 
[16] A. Darwiche, C. Marino, M.T. Sougrati, B. Fraisse, L. Stievano, L. Monconduit, Better cycling performances of bulk sb in Na-ion batteries compared to Li-ion systems: an unexpected electrochemical mechanism, J. Am. Chem. Soc. 134 (2012) 20805-20811.

[17] P. Extance, S.R. Elliott, Pressure dependence of the electrical conductivity of amorphous red phosphorus, Philosophical Magazine Part B 43 (1981) 469-483.

[18] J. Sun, G. Zheng, H.W. Lee, N. Liu, H. Wang, H. Yao, W. Yang, Y. Cui, Formation of stable phosphorus-carbon bond for enhanced performance in black phosphorus nanoparticle-graphite composite battery anodes, Nano Lett. 14 (2014) 4573-4580.

[19] J. Qian, X. Wu, Y. Cao, X. Ai, H. Yang, High capacity and rate capability of amorphous phosphorus for sodium ion batteries, Angew. Chem. Int. Ed. 52 (2013) 4633-4636.

[20] Y. Kim, Y. Park, A. Choi, N.S. Choi, J. Kim, J. Lee, J.H. Ryu, S.M. Oh, K.T. Lee, An amorphous red phosphorus/carbon composite as a promising anode material for sodium ion batteries, Adv. Mater. 25 (2013) 3045-3049.

[21] J. Qian, D. Qiao, X. Ai, Y. Cao, H. Yang, High capacity and rate capability of amorphous phosphorus for sodium ion batteries, Chem. Commun. 48 (2012) 8931-8933.

[22] W. Li, S. Chou, J. Wang, H. Liu, S. Dou, Simply mixed commercial red phosphorus and carbon nanotube composite with exceptionally reversible sodium-ion storage, Nano Lett. 13 (2013) $5480-5484$.

[23] Y. Zhu, Y. Wen, X. Fan, T. Gao, F. Han, C. Luo, S. Liou, C. Wang, Red phosphorus-single-walled carbon nanotube composite as a superior anode for sodium ion batteries, ACS Nano 9 (2015) 3254-3264.

[24] J. Song, Z. Yu, M.L. Gordin, S. Hu, R. Yi, D. Tang, T. Walter, M. Regula, D. Choi, X. Li, A. Manivannan, D. Wang, Chemically bonded phosphorus/graphene hybrid as a high performance anode for sodium-ion batteries, Nano Lett. 14 (2014) 6329-6335.

[25] H. Wu, G. Chan, J. W. Choi, I. Ryu, Y. Yao, M.T. McDowell, S.W. Lee, A. Jackson, Y. Yang, L. Hu, Y. Cui, Stable cycling of double-walled silicon nanotube battery anodes through solid-electrolyte interphase control, Nature Nanotechnol. 7 (2012) 310-315.

[26] N. Liu, Z. Lu, J. Zhao, M.T. McDowell, H.W. Lee, W. Zhao, Y. Cui, A pomegranate-inspired nanoscale design for large-volume-change lithium battery anodes, Nature Nanotechnol. 9 (2014) 187-192. 
[27] J. Sun, H.W. Lee, M. Pasta, H. Yuan, G. Zheng, Y. Sun, Y. Li, Y. Cui, A phosphorene-graphene hybrid material as a high-capacity anode for sodium-ion batteries, Nature Nanotechnol. 10 (2015) 980-985.

[28] Corbridge, D. E. C. Phosphorus chemistry, biochemistry and technology, Sixth Edition. 119 (2013).

[29] G. Li, Y. Li, H. Liu, Y. Guo, Y. Li, D. Zhu, Architecture of graphdiyne nanoscale films, Chem. Commun. 46 (2010) 3256-3258.

[30] J. Sun, H. Liu, Xu Chen, D. G. Evans, W. Yang, X. Duan, Synthesis of graphene nanosheets with good control over the number of layers within the two-dimensional galleries of layered double hydroxides, Chem. Commun. 48 (2012) 8126-8128. 


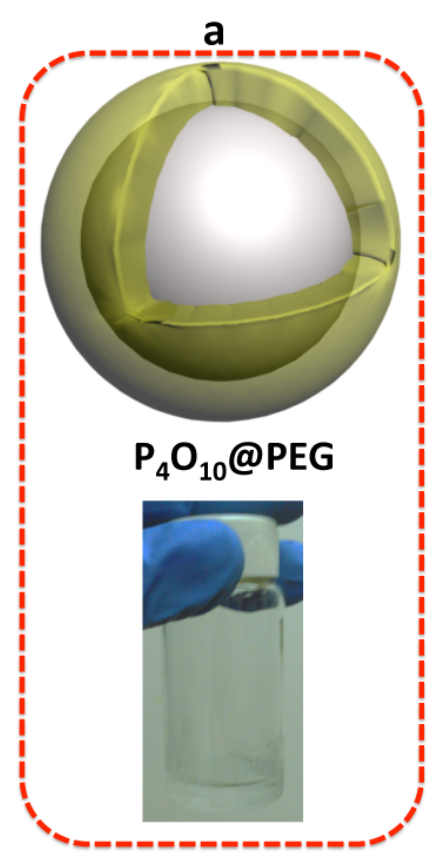

PEG
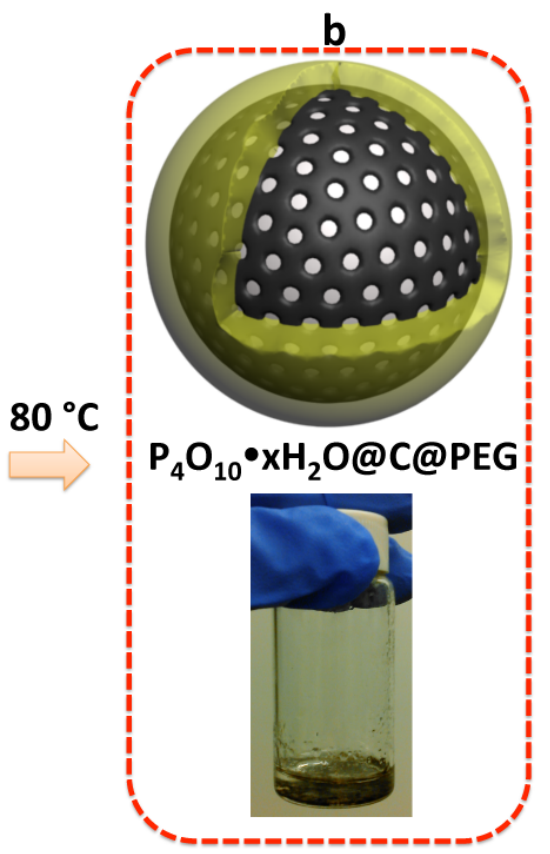

$900^{\circ} \mathrm{C}$
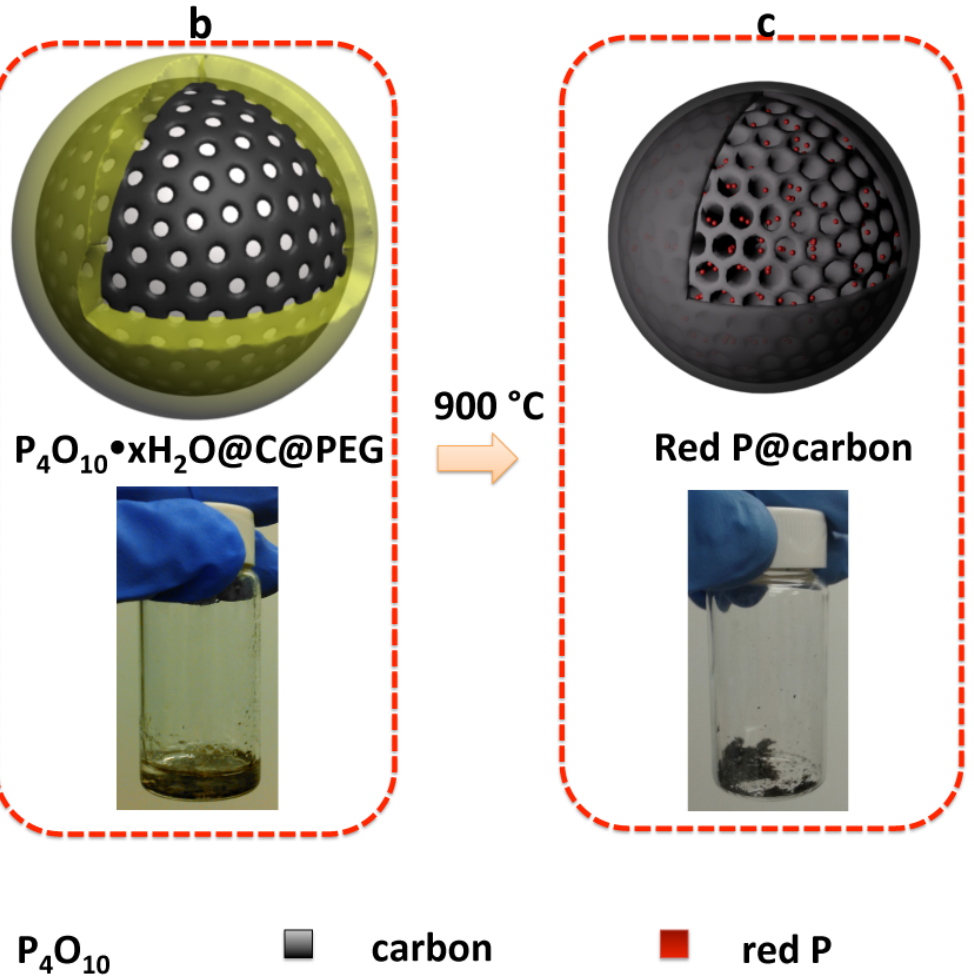

$\operatorname{red} P$

Figure 1| Schematic and digital photographs of the synthesis procedure for the ultrafine red phosphorus particles embedded in a $3 \mathrm{D}$ carbon framework ( $\mathrm{P} / \mathbf{C}$ composite). (a) $\mathrm{P}_{4} \mathrm{O}_{10}$ coated with PEG. (b) $\mathrm{P}_{4} \mathrm{O}_{10} \cdot \times \mathrm{H}_{2} \mathrm{O}$ coated with carbon and PEG. (c) the $\mathrm{P} / \mathrm{C}$ composite. 


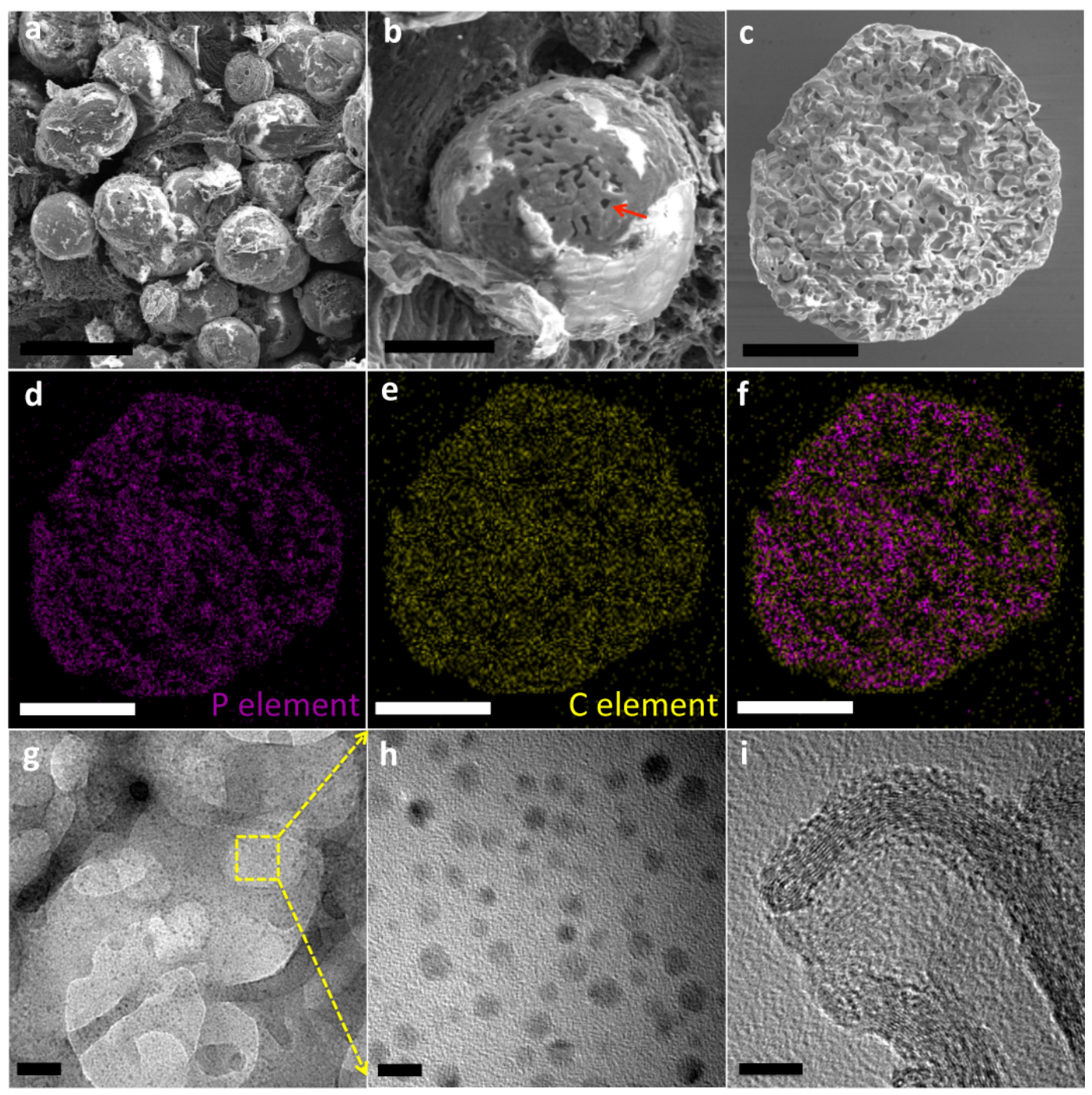

Figure 2 | SEM and TEM characterization of the P/C composite. (a) Low magnification SEM image (Scale bar, $20 \mathrm{~m}$ ). (b) High magnification SEM image of a single sphere at (Scale bar, $10 \mathrm{~m}$ ). (c) SEM image of a cracked $\mathrm{P} / \mathrm{C}$ sphere (Scale bar, $10 \mathrm{~m}$ ). The corresponding EDS elemental dot-mapping images of (d) P, (e) C elements and (f) overlay of C and P (Scale bar, $10 \mathrm{~m}$ ). (g) TEM image of the P/C composite (Scale bar, $100 \mathrm{~nm}$ ). (h) Enlarged HRTEM image of the selected area in (g), with a scale bar of $10 \mathrm{~nm}$. (i) HRTEM image of carbon framework (Scale bar, $10 \mathrm{~nm}$ ). 

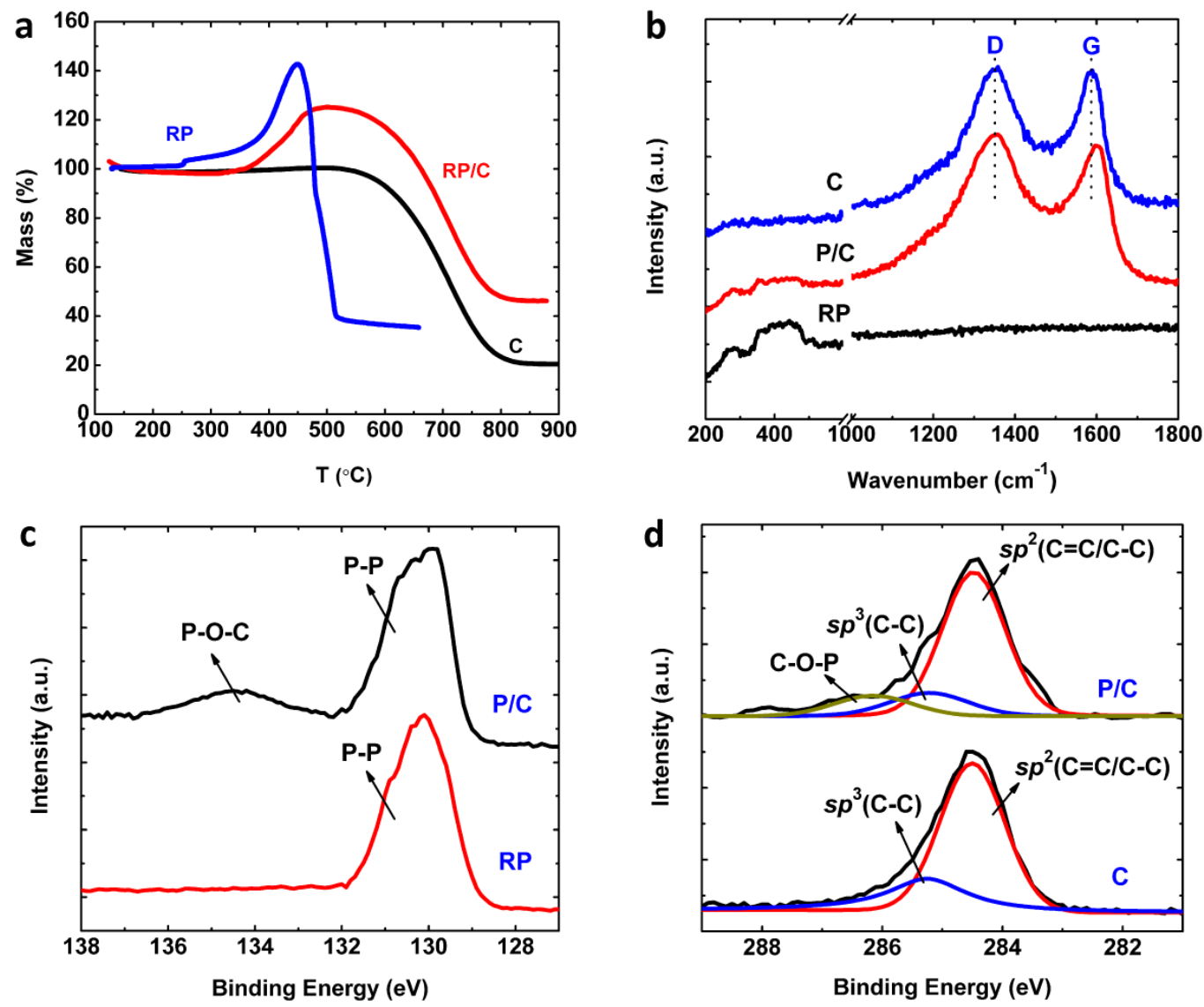

Figure 3 | Structural characterization of the P/C composite. (a) TG analysis of the P/C composite, red $\mathrm{P}$ and carbon framework in an air. (b) Raman spectra of the $\mathrm{P} / \mathrm{C}$ composite, red $\mathrm{P}$ and carbon framework. (c) P2 $p$ XPS spectra of the P/C composite and red P. (d) C1s XPS spectra of the P/C composite and carbon framework. (The P/C composite, red P and carbon framework only are labeled $\mathrm{P} / \mathrm{C}, \mathrm{RP}$ and $\mathrm{C}$, respectively.) 

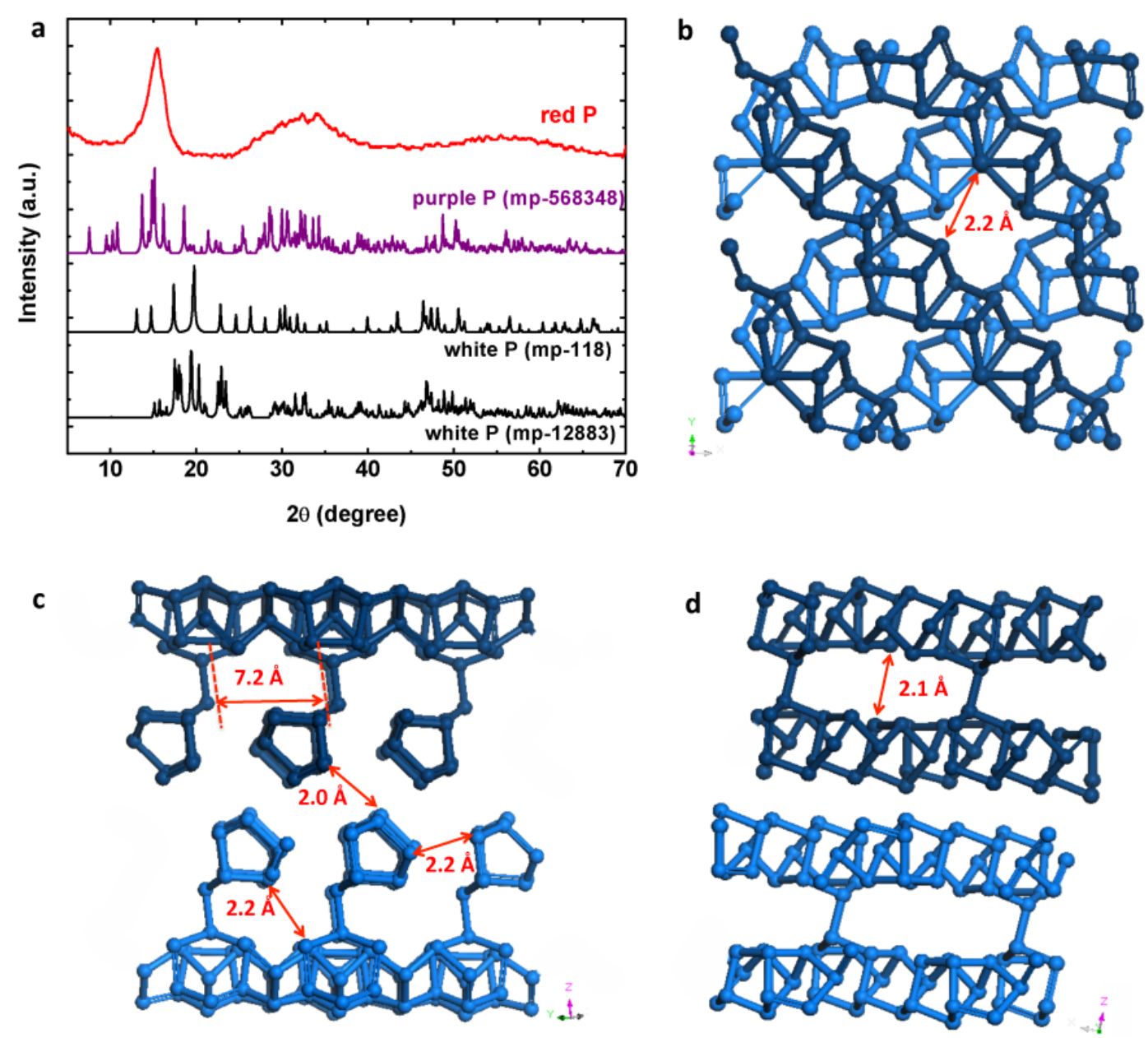

Figure 4 | Crystal structure and initial sodiation process of the as-synthesized red phosphorus. (a)

The XRD spectrum of the as-synthesized red phosphorus (upper panel) and the powder diffraction files of purple $\mathrm{P}$ (mp-715463, IUCr) and two different phases of white $\mathrm{P}$ (mp-118 and mp-12883). A view of purple P crystal structure with the size-labeled channels for ion intercalation, along (b) [001], (c) [110] (d) [010] direction, respectively. 

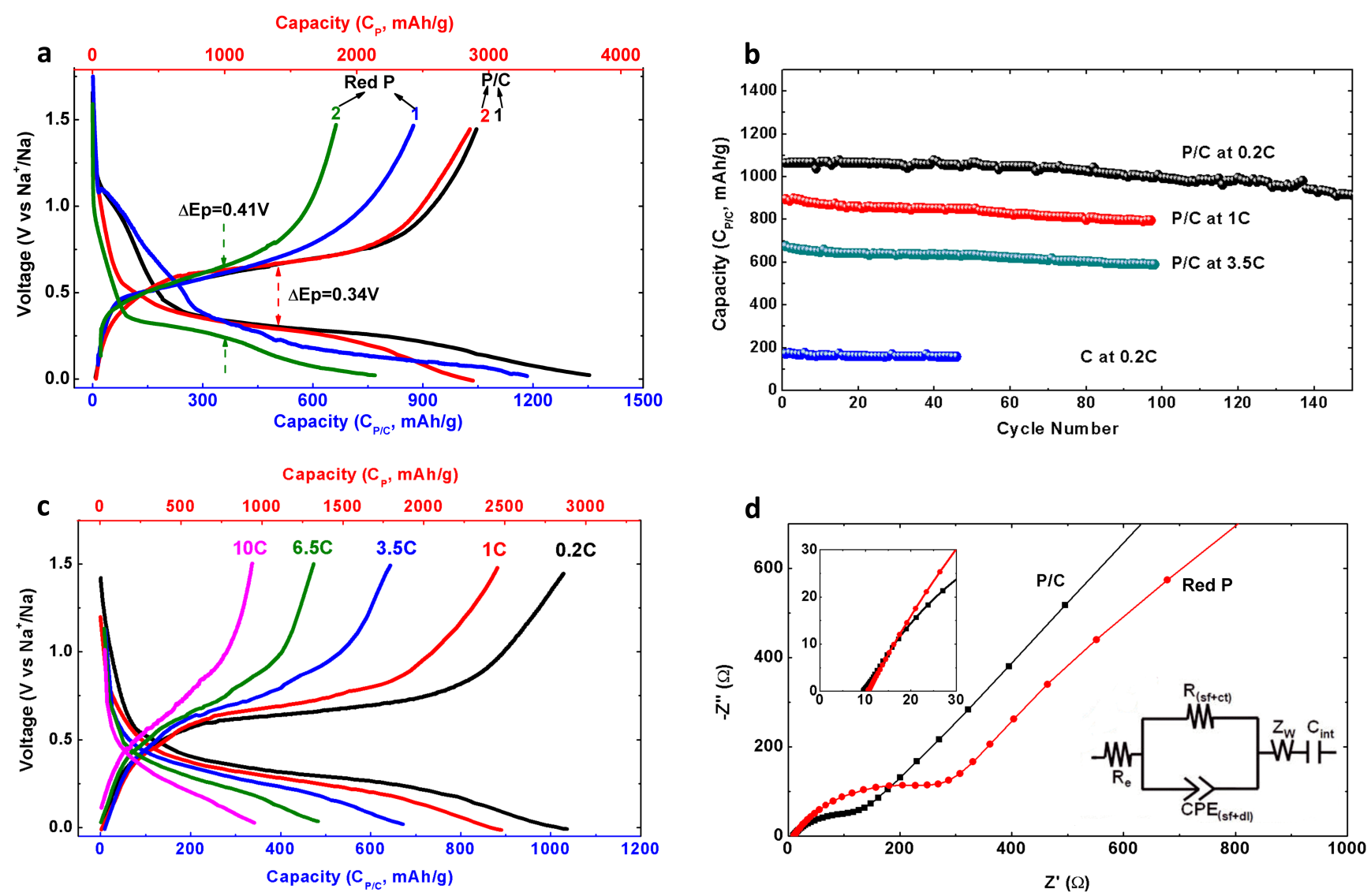

e



Figure 5 | Electrochemical sodium storage performance and structural evolution of the $\mathrm{P} / \mathrm{C}$

composite. (a) The galvanostatic charge-discharge profiles of red $\mathrm{P}$ and $\mathrm{P} / \mathrm{C}$ electrodes at the first two cycles between $0.01-1.5 \mathrm{~V}$ with a current density of $0.2 \mathrm{C}$. (b) the cycling performance of the carbon framework alone and the $\mathrm{P} / \mathrm{C}$ composite at different current densities of $0.2 \mathrm{C}, 1 \mathrm{C}$ and $3.5 \mathrm{C}$. (c) the rate performance of the $\mathrm{P} / \mathrm{C}$ electrode at various current densities from 0.2 to $10 \mathrm{C} . \mathrm{C}_{\mathrm{P}}$ and $\mathrm{C}_{\mathrm{P} / \mathrm{C}}$ are for the specific capacity calculated based on the weight of red P and P/C composite, respectively. (d) Nyquist plots and equivalent circuit model of $\mathrm{P} / \mathrm{C}$ composite and red $\mathrm{P}$ electrodes after 5 cycles in discharged state. (e) SEM image of P/C sphere at full sodiated state for the 20th cycle, and the corresponding EDS elemental dot-mapping images of $\mathrm{Na}, \mathrm{P}$, and $\mathrm{C}$ elements (Scale bar, $10 \mathrm{~m}$ ). 